Original Article

\title{
OSTEOPOROTIC FRACTURE RISK IN RHEUMATOID ARTHRITIS
}

\author{
TANYA SYNGLE ${ }^{1}$, SUDEEP KAUR $^{2}$, NIDHI GARG ${ }^{3}{ }^{*}$
}

${ }^{1}$ Healing Touch Foundation, \#547, Sector 16 D, Chandigarh, India, 160015, ${ }^{2}$ Healing Touch City Clinic, \#547, Sector 16 D, Chandigarh, India, 160015, ${ }^{3}$ Chitkara College of Pharmacy, Chitkara University, Rajpura, Punjab, India, 140401

Email: nidhi_garg08@yahoo.co.in

Received: 23 Sep 2017 Revised and Accepted: 25 Jan 2018

\section{ABSTRACT}

Objective: Osteoporosis is an extra-articular complication of rheumatoid arthritis (RA) with increased risk of fractures. FRAX is an online tool for assessing risk of osteoporotic fracture. However, the relationship between the FRAX score and disease specific risk factors has not yet been investigated in RA. Hence, we assessed 10-year fracture risk using FRAX and its relationship with disease activity score, inflammation and disease duration in RA.

Methods: 50 RA patients enrolled and recruited consecutively in a special camp organized for RA patients on the occasion of World Osteoporosis Day, 2016to estimate the osteoporotic fracture risk from Rheumatology clinic. Predicted 10-year risk of hip fracture and major osteoporotic fracture (MOF) by FRAX score without information on bone mineral density (BMD). Inflammatory disease activity measures included disease activity score of 28 joints (DAS28), erythrocyte sedimentation rate (ESR) and C-reactive protein (CRP) were also measured. FRAX score also estimated in 40 age and sex matched healthy controls.

Results: FRAX estimated significantly enhanced fracture risk in active RA, both for MOF (13.34 $\pm 1.26 \%)$ and hip fracture (6.84 $\pm 1.03 \%)$ as compared to controls for MOF (5.46 $\pm 0.95 \%)$ and hip fracture $(1.97 \pm 0.49 \%)$. In RA patients, MOF and hip fracture risk correlated with DAS28 and disease duration and MOF risk correlated with ESR and CRP.

Conclusion: Active RA patients, even in the absence of BMD have an increased FRAX score indicating an enhanced 10-year probability of MOF and hip fracture. Long disease duration, high disease activity and an elevated ESR and CRP are potential disease specific risk factors for osteoporotic fractures in RA.

Keywords: Rheumatoid arthritis, FRAX, Osteoporosis, Disease activity, Inflammation

(C) 2018 The Authors. Published by Innovare Academic Sciences Pvt Ltd. This is an open access article under the CC BY license (http://creativecommons.org/licenses/by/4.0/) DOI: http://dx.doi.org/10.22159/ijpps.2018v10i3.22751

\section{INTRODUCTION}

Rheumatoid arthritis (RA) is a chronic inflammatory and destructive joint disease characterized by chronic, progressive, systemic inflammation leading to substantial pain, disability, and other morbidities [1, 2]. Osteoporosis (OP) is an extra-articular complication of RA that results in increased risk of fractures and associated morbidity, mortality, and health care costs [3, 4]. The incidence of osteoporosis among patients with rheumatoid arthritis is $15-20 \%$ at the hip and spine [5].

In RA, bone metabolism is altered by the chronic inflammatory process via activation/inhibition of bone cell function [6], modification of body composition, corticosteroid use [7], diet [8] and low levels of physical activity. Moreover, during the active phase of the disease, elevated plasma concentrations of inflammatory cytokines, i.e. Interleukin-1 (IL-1), interleukin-6 (IL-6) and tumor necrosis factor-alpha (TNF- $\alpha$ ) lead to reductions in fat-free mass with a loss of body cell mass and consequent reduction in muscle strength $[9,10]$. This loss may negatively affect bone mineral density (BMD) because lean mass is a predictor of bone mass through its mechanical pull on the skeleton [11].

The World Health Organization Fracture Risk Assessment Tool (FRAX) estimates a 10-year probability of sustaining a hip fracture and other major osteoporotic fractures (spine, forearm, hip, shoulder) [12] based on specific risk factors. The reasons for increased fracture risk in RA are complex. It may be due to chronic inflammation, inactivity and an increased risk of falling. Therefore, RA has been incorporated as a dichotomy (Yes or No) predictor in the FRAX algorithm and intuitively, one would expect that more severe or active disease would be associated with more severe osteoporosis [13]. However, risk factors of osteoporosis fracture in RA have not been well elucidated. Hence, we investigated disease specific risk factors that make an RA patient more prone to osteoporosis risk and also assessed 10-year fracture risk using country specific FRAX and its relationship with the disease duration, disease activity score and inflammation in RA patients.

\section{MATERIALS AND METHODS}

\section{Patients}

Fifty RA patients fulfilling 2010 Rheumatoid Arthritis Classification Criteria were enrolled in this observational study from a Rheumatology outpatient clinic. It was a special camp organized for RA patients on the occasion of World Osteoporosis Day, 2016 [14] to estimate the osteoporotic fracture risk and the event was publicized previously. All consecutive RA patients who reported for the camp were recruited in this survey. FRAX score was also estimated in 40 age and sex matched healthy controls. Healthy controls were recruited from among the hospital clinic staff and the patient attendants.

All the patients included had active RA defined by the presence of disease activity score of 28 joints (DAS28>3.2). Eligible patients were biologic naïve and on stable doses of synthetic disease modifying anti-rheumatic drugs (DMARDs) [methotrexate (15 $\mathrm{mg} /$ week), hydroxychloroquine (400 mg/day), sulfasalazine $(2-3$ $\mathrm{g} /$ day $)$ or leflunomide $(20 \mathrm{mg} /$ day $)]+$ oral glucocorticoids $(\leq 10$ $\mathrm{mg}$ /day prednisone or equivalent) before entering the study.

\section{Assessment of inflammatory disease activity}

- DAS28 was used to assess disease activity of 28 joints by a composite measure, which is a linear sum of four parameters including tender joint count (TJC), swollen joint count (SJC), patient global assessment of general health on a visual analogue scale (VAS), and erythrocyte sedimentation rate (ESR) [15].

- ESR was measured by Westergren method.

- C-reactive protein (CRP) level was determined using a standard commercial kit. 


\section{Assessment of FRAX score}

Predicted $10 \mathrm{y}$ risks of hip fracture and major osteoporotic fracture (MOF) were calculated online by India specific FRAX without information on BMD for every patient. FRAX predictors determined included: age at index date, sex, BMI (most recent), previous fracture at any site (ever before, yes/no), parent fractured hip, current smoking status (most recent; yes/no), alcohol use (the daily number of units was $\geq 3$, yes/no), oral glucocorticoid use (yes/no), RA (ever before, yes/no) and secondary osteoporosis.

\section{Ethics approval}

This survey was done as a part of the World Osteoporosis Day activity at our Rheumatology clinic. Ethics approval was not required for this study as it was not affecting the patient's integrity.

\section{Statistical analysis}

Results were expressed as mean \pm standard error of mean (SEM). Descriptive analysis was done according to different parameters and Pearson correlation analysis was used to evaluate the correlation between FRAX score (10-year MOF and hip fracture risk) and disease activity, disease duration and inflammatory disease variables. A two-sided $\mathrm{p}<0.05$ was considered statistically significant. Statistical analysis was done using the sigma stat 3.5 version for Windows 7.0.

\section{RESULTS}

The demographic and clinical characteristics of RA patients and healthy controls are presented in table 1 . The mean age $( \pm \mathrm{SEM})$ of the patients was $67.62 \pm 1.05 \mathrm{y}$ with a mean disease duration of $10.19 \pm 1.38 \mathrm{y}$.

Table 1: Demographic and disease characteristics of rheumatoid arthritis patients and healthy controls

\begin{tabular}{|c|c|c|c|}
\hline Variables & Rheumatoid arthritis & Controls & p-value \\
\hline Age,years & $67.62 \pm 1.05$ & $66.03 \pm 1.95$ & NS \\
\hline $\operatorname{Sex}(F: M)$ & $46: 4$ & $34: 6$ & \\
\hline Disease Duration,yrs & $10.19 \pm 1.38$ & -- & -- \\
\hline $\mathrm{BMI}, \mathrm{kg} / \mathrm{m}^{2}$ & $26.73 \pm 0.90$ & $25.78 \pm 0.72$ & 0.23 \\
\hline MOF (\%) & $13.34 \pm 1.26$ & $5.46 \pm 0.95$ & $0.01 *$ \\
\hline HF (\%) & $6.84 \pm 1.03$ & $1.97 \pm 0.49$ & $0.001^{*}$ \\
\hline DAS28-ESR & $5.42 \pm 0.20$ & --- & \\
\hline ESR, mm $1^{\text {sthour }}$ & $44.08 \pm 2.94$ & $16.85 \pm 0.70$ & $0.01 *$ \\
\hline $\mathrm{CRP}, \mathrm{mg} / \mathrm{dl}$ & $16.39 \pm 3.00$ & $3.84 \pm 0.16$ & 0.01* \\
\hline
\end{tabular}

Values are expressed as mean \pm SEM, $n=50$-number of rheumatid arthritis patients, $n=40$ number of healthy controls, F-Female, M-Male, BMI-body mass index, MOF-major osteoporotic fracture, HF-hip fracture, ESR-erythrocyte sedimentation rate, CRP-C-reactive protein, DAS28-disease activity score of 28 joint counts. ${ }^{*} \mathrm{p}<0.05$, statistically significant

\section{Assessment of disease activity scores}

All of the study patients had an active disease with moderate to high disease activity, as reflected by DAS 28 score $\geq 3$. 2 . The mean DAS28 score in the participating RA patients was $5.42 \pm 0.20$.

\section{Assessment of the inflammatory profile}

In order to establish the inflammatory status, we assessed the values of ESR and CRP. The levels of inflammatory measures, ESR $(p<0.01)$ and CRP $(p<0.03)$ were significantly higher in RA patients as compared with healthy controls (table 1).

\section{Assessment of FRAX score}

In order to assess the fracture risk, we used the FRAX algorithm that showed the 10-year risk for a MOF and hip fracture was significantly $(\mathrm{p}<0.05)$ higher in RA patients as compared to healthy controls (table 1).

\section{Association of FRAX scores with disease activity and disease duration}

Pearson correlation analysis was performed to investigate the relationship between MOF, hip fracture with DAS28, inflammatory measures and disease duration. In RA patients, 10-year MOF and hip fracture risk positively correlated with DAS $28(\mathrm{r}=0.64, \mathrm{p}=0.002)$, $(\mathrm{r}=0.52, \mathrm{p}=0.01)$, disease duration $(\mathrm{r}=0.58, \mathrm{p}=0.001)(\mathrm{r}=0.51$, $\mathrm{p}=0.01)$ and $\operatorname{CRP}(\mathrm{r}=0.54, \mathrm{p}=0.01)(\mathrm{r}=0.55, \mathrm{p}=0.001)$ respectively (table 2). There was a significant correlation between 10-year MOF and ESR ( $\mathrm{r}=0.39, \mathrm{p}=0.04)$ indicating that high fracture risk was associated with inflammation.

Table 2: Correlation of FRAX score with disease variables in rheumatoid arthritis patients

\begin{tabular}{llll}
\hline Variables & MOF & Hip fracture & \\
\hline Disease duration,yrs & 0.58 & 0.51 \\
BMI, kg/m & 0.32 & $0.01^{*}$ & 0.22 \\
DAS28-ESR & 0.64 & 0.12 & 0.52 \\
ESR, mm 1 & 0.39 & $0.04^{*}$ & 0.31 \\
CRP, mg/dl & 0.54 & $0.04^{*}$ & 0.15 \\
\hline
\end{tabular}

BMI-body mass index, ESR-erythrocyte sedimentation rate, DAS28-disease activity score of 28 joint counts, CRP-C-reactive protein, *p<0.05, Statistically significant

\section{DISCUSSION}

The present study is novel for several reasons. This study demonstrates that in patients with active RA, even in the absence of information on BMD, FRAX algorithm predicts a high 10-year risk probability of MOF and hip fracture as compared to controls. It has also suggested that longer disease duration, high disease activity and an elevated ESR and CRP are potential risk factors for $10 \mathrm{y}$ probability of fracture in RA. To the best of our knowledge, this is the first study to report a plausible association between FRAX score (10 y MOF and hip fracture probability) and disease-specific risk factors (disease duration, DAS 28, ESR and CRP) responsible for fracture in patients with RA without information on BMD. Although FRAX score and disease activity measures, as well as some other factors, have previously been assessed by other investigators in RA patients [16,17], our results regarding the relationship of FRAX score with disease duration, high disease activity, ESR and CRP levels without BMD are novel and possibly contribute to the proof of the causative mechanisms of osteoporosis in RA.

The prevalence of osteoporosis in RA patients is approximately twice that in the general population [18]. RA is the only secondary 
cause of osteoporosis that is considered independent of bone density in the FRAX algorithm [19]. The underlying reasons for the increased fracture risk in RA are complex. These may include chronic inflammation, increased disease activity, impaired physical activity and an increased risk of falling $[20,21]$. The various risk factors for osteoporosis are history of fracture, gender, age, family history of osteoporosis, estrogen deficiency, low calcium intake, vitamin D deficiency, use of corticosteroids, smoking and alcohol consumption [22] but the present study focused on the diseasespecific risk factors associated with RA like age, sex, disability, previous non-vertebral fracture, disease duration, active disease and use of glucocorticoids. Although many studies document a correlation between various parameters of disease activity or severity and decreased bone density, the relationship between the FRAX score and disease-specific measures have not yet been explored for both MOF and hip fracture in RA. Hence, using the FRAX algorithm, we assessed fracture risk and its relationship with the disease duration, disease activity score and inflammatory measures in RA patients.

In the present study, country-specific FRAX score has indicated an increased 10 y risk of MOF and hip fracture in patients with RA as compared to healthy controls. Other studies have also shown a similar increase in FRAX score in RA patients [23]. The mean of MOF risk (13.34\%) and hip fracture risk (6.84\%) observed in the present study is comparable to that reported by Klop et al. [23].

RA may appear to be a risk factor for fractures only through association with other risk factors which are more directly responsible for the observed effects [17]. Conventional risk factors for osteoporosis in RA include the use of glucocorticoids, longer disease duration, high disability scores, low body weight and age [24]. Our data seem to favour this possibility, and the factors which appeared to have the most predictive value were disease duration, inflammatory state and severity of the disease process. Present study results observed a relationship between FRAX score (10 y MOF and hip fracture probability) and disease duration. Disease duration was the strongest predictor of future fractures in this study with a disease duration of $>10 \mathrm{y}$. Our study results are in accordance with the previous study that demonstrated a significant association of incident fractures with duration of disease [16]. This might be due to the fact that RA patients have been exposed for greater lengths of time to risk factors for bone loss such as corticosteroid use, lower estrogen levels, prolonged immobilization and greater inflammatory state.

The DAS28 is a widely used score for evaluation of disease activity in RA [15]. Previous studies have associated various disease parameters seen in RA patients with disease duration [16] and DAS28 $[25,26]$. A recent study by Ileana et al. showed that DAS28 were statistically associated with osteoporosis in RA patients [27]. In the present study, DAS28 correlates with a 10 y MOF and hip fracture risk in RA patients. Our study is the first to convincingly show the association of DAS28 with MOF and hip fractures in RA patients. This indicating an active disease and its severity are potential risk factors for osteoporotic fracture in RA.

Chronic inflammation has been recognized as a potential risk factor for osteoporosis and fracture [28]. In the present study, higher levels of ESR and CRP in RA as compared with controls depict enhanced inflammatory state responsible for increased fracture risk in RA. Our study results suggest a significant association of the inflammatory process itself represented by an elevated ESR and CRP in RA patients.

In a recent study of American women (mean age 46 y, 194 fractures) published by Ishii and colleagues, fracture hazard increased significantly for values of hs-CRP above $3 \mathrm{mg} / \mathrm{l}$ [29]. The Health Aging and Body Composition Study also showed that the incidence of fracture was also highest in subjects with the highest CRP and IL-6 but the trend was not statistically significant [30]. However, in the present study, a significant association of CRP with both MOF and hip fracture and association of ESR with MOF in RA patients showed that how low-grade inflammation leads to an increased risk for fractures in RA. This suggests in patients with RA, the degree of the inflammatory process as assessed by ESR and CRP, predicts a bone loss and might be of value in identifying patients at risk of developing osteoporosis and offers clues as to the mechanism of such an effect.

\section{LIMITATIONS}

The present study has some limitations, the number of patients was relatively small, and the current study was a single-centre study. There are limitations to the FRAX guidelines. FRAX does not incorporate every clinical variable that may be important in fracture risk assessment (e. g., fall risk) and lacks information on doseresponse relationships (e. g., glucocorticoid, DMARD, biologic dose). Nonetheless, FRAX represents an important starting point in the complex task of risk assessment and fracture prevention, but should not be regarded as a substitute for clinical judgment. Several important operational issues need to be considered in using FRAX as part of day-to-day patient care. Other factors such as exposure to DMARDs and treatment status also need to be considered before any therapeutic decision is taken to manage the osteoporotic risk.

Despite its limitations, this study has notable strengths. It provides an important insight into the association of FRAX score and diseasespecific factors that can influence therapeutic strategies.

\section{CONCLUSION}

We conclude that the $10 \mathrm{y}$ fracture probability in RA estimated with the FRAX algorithm is increased and is associated with long disease duration, disease severity and inflammatory disease burdendisease-specific risk factors. The various factors observed during the camp like longer disease duration increased disease severity and increased inflammatory markers affected the overall score as they increased the risk. Hence, use of FRAX without BMD may be appropriate when BMD is not readily available or to identify individuals who may benefit from a BMD measurement.

\section{ABBREVIATIONS}

RA-rheumatoid arthritis, BMD-bone mineral density, MOF-major osteoporotic fracture, DAS28-disease activity score of 28 joints, ESRerythrocyte sedimentation rate, CRP-C-reactive protein, OPosteoporosis, IL-1-interleukin 1, IL-6-interleukin-6, TNF- $\alpha$-tumor necrosis factor-alpha, DMARDs-disease modifying anti-rheumatic Drugs, TJC-tender joint count, SJC-swollen joint count, VAS-patient global assessment of general health on a visual analogue scale, BMIbody mass index, SEM-standard error of mean.

\section{ACKNOWLEDGEMENT}

None

\section{AUTHORS CONTRIBUTIONS}

Tanya Syngle: Data analysis, FRAX estimation, drafting article, critical revision of the article.

Sudeep Kaur: Sample and data collection

Nidhi Garg: Data analysis, writing manuscript, critical revision of the article.

\section{CONFLICT OF INTERESTS}

The authors declared no potential conflicts of interest with respect to the authorship, research, or publication of this article.

\section{REFERENCES}

1. Kim SY, Schneeweiss S, Liu J, Daniel GW, Chang CL, Garneau K, et al. Risk of osteoporotic fracture in a large population-based cohort of patients with rheumatoid arthritis. Arthritis Res Ther 2010;12:R154.

2. Priyadarsini R, Menaka A. Design and synthesis of some newer imidazolyl heterocycles as potent btk inhibitors for the treatment of rheumatoid arthritis. Int J Curr Pharm Res 2017;9:80-3.

3. Deodhar AA, Woolf AD. Bone mass measurement and bone metabolism in rheumatoid arthritis: a review. Br J Rheumatol 1996;35:309-22.

4. Westhovens R, Dequeker J. Rheumatoid arthritis and osteoporosis. Z Rheumatol 2000;59:33-8.

5. Lodder MC, Haugeberg G, Lems WF, Uhlig T, Orstavik RE, Kostense PJ, et al. Radiographic damage associated with low bone mineral density and vertebral deformities in rheumatoid 
arthritis: the oslo-truro-amsterdam (OSTRA) collaborative study. Arthritis Rheum 2003;49:209-15.

6. Bezerra MC, Carvalho JF, Prokopowitsch AS, Pereira RM. RANK, RANKL and osteoprotegerin in the arthritic bone loss. Braz J Med Biol Res 2005;38:161-70.

7. Van Staa TP. The pathogenesis, epidemiology and management of glucocorticoid-induced osteoporosis. Calcif Tissue Int 2006;79:129-37.

8. Stone J, Doube A, Dudson D, Wallace J. Inadequate calcium, folic acid, vitamin E, zinc, and selenium intake in rheumatoid arthritis patients: results of a dietary survey. Semin Arthritis Rheum 1997;27:180-5.

9. Roubenoff R, Roubenoff RA, Cannon JG, Kehayias JJ, Zhuang H, Dawson-Hughes B, et al. Rheumatoid cachexia: cytokine-driven hypermetabolism accompanying reduced body cell mass in chronic inflammation. J Clin Invest 1994;93:2379-86.

10. Manikandan N, Arunagirinathan N, Priya K, Vijaykanth N, Rameshkumar MR, Balakrishnan S. Tumor necrosis factoralpha level in sera of South Indian patients with rheumatoid arthritis: correlation with anti-cyclic citrullinated peptide antibody level. Asian J Pharm Clin Res 2017;10:118-20.

11. Beck TJ, Oreskovic TL, Stone KL, Ruff CB, Ensrud K, Nevitt MC, et al. Structural adaptation to changing skeletal load in the progression toward hip fragility: the study of osteoporotic fractures. J Bone Miner Res 2001;16:1108-19.

12. Kanis JA, Borgstrom F, Laet C, Johansson H, Johnell O, Jonsson $\mathrm{B}$, et al. Assessment of fracture risk. Osteoporos Int 2005; 16:581-9.

13. Broy SB. Tanner SB on behalf of the FRAX. position development conference members. official positions for FRAX: clinical regarding rheumatoid arthritis. J Clin Densitometry: Assessment Skeletal Health 2011;14:184-9.

14. Aletaha D, Neogi T, Silman AJ, Funovits J, Felson DT, Bingham CO, et al. Rheumatoid arthritis classification criteria. Arthritis Rheum 2010;62:2569-81.

15. Salaffi F, Ciapetti A. Clinical disease activity assessments in rheumatoid arthritis. Int J Clin Rheumatol 2013;8:347-60.

16. van Staa TP, Geusens P, Bilsma JW, Leufkens HG, Cooper C. Clinical assessment of the long-term risk of fracture in patients with rheumatoid arthritis. Arthritis Rheum 2006;54:3104-12.

17. Hooyman JR, Melton J, Nelson AM, O'Fallon WM, Riggs BL. Fractures after rheumatoid arthritis: a population-based study. Arthritis Rheum 1984;27:1353-61.

18. Haugeberg G, Uhlig T, Falch JA, Halse JI, Kvien TK. Bone mineral density and frequency of oteoporosis in female patients with rheumatoid arthritis: results from 394 patients in the oslo county rheumatoid arthritis register. Arthritis Rheum 2000;43:522-30.

19. Kanis JA on behalf of the World Health Organization Scientific Group. Assessment of osteoporosis at the primary health-care level. Technical Report. World Health Organization Collaborating Centre for Metabolic Bone Diseases, University of Sheffield, UK.: Printed by the University of Sheffield; 2007.

20. Dirven L, Van denBroek M, van Groenendael JHLM, Beus WM, Kerstens PJSM, Huizinga TW, et al. Prevalence of vertebral fractures in a disease activity steered cohort of patients with early active rheumatoid arthritis. BMC Musculoskelet Disord 2012;13:125.

21. Kaz H, Johnson D, Kerry S, Chinappen U, Tweed K, Patel S. Fallrelated risk factors and osteoporosis in women with rheumatoid arthritis. Rheumatology (Oxford) 2004;43:1267-71.

22. Sozen T, Ozisik L, Basaran NC. An overview and management of osteoporosis. Eur J Rheumatol 2017;4:46-56.

23. Klop C, De vries F, Bijlsma JW, Leufkens HG, Welsing PM. Predicting the $10 \mathrm{y}$ risk of hip and major osteoporotic fracture in rheumatoid arthritis and in the general population: an independent validation and update of UK FRAX without bone mineral density. Ann Rheum Dis 2016;75:2095-100.

24. Lee JH, Sung YK, Choi CB, Cho SK, Bang SY, Choe JY, et al. The frequency of and risk factors for osteoporosis in Korean patients with rheumatoid arthritis. BMC Musculoskelet Disord 2016;17:98.

25. Kvien T, Haugeberg G, Uhlig T, Falch JA, Halse JI, Lems WF, et al. Data driven attempt to create a clinical algorithm for identification of women with rheumatoid arthritis at high risk of osteoporosis. Ann Rheum Dis 2000;59:805-11.

26. Laan RF, Buijs WC, Verbeek AL, Draad MP, Corstens FH, van de Putte LB, et al. Bone mineral density in patients with recent onset rheumatoid arthritis: influence of disease activity and functional capacity. Ann Rheum Dis 1993;52:21-6.

27. Ileana MC, Nelutu MA. The relationship between physical disability, disease activity and osteoporosis in patients with rheumatoid arthritis. Arch Rheumatol 2014;29:273-9.

28. McLean R. Proinflammatory cytokines and osteoporosis. Curr Osteoporos Rep 2009;7:134-9.

29. Ishii S, Cauley JA, Greendale GA, Crandall CJ, Danielson ME, Ouchi Y, et al. C-reactive protein, bone strength, and $9 \mathrm{y}$ fracture risk: Data from the study of women's health across the nation (SWAN). J Bone Miner Res 2013;28:1688-98.

30. Cauley J, Danielson M, Boudreau R, Forrest K, Zmuda J, Pahor $\mathrm{M}$, et al. Inflammatory markers and incident fracture risk in older men and women: the health aging and body composition study. J Bone Miner Res 2007;22:1088-95. 